\title{
Protein synthesis underlies post-retrieval memory consolidation to a restricted degree only when updated information is obtained
}

\author{
Carlos J. Rodriguez-Ortiz, Vanesa De la Cruz, Ranier Gutiérrez, and \\ Federico Bermudez-Rattoni ${ }^{1}$ \\ Departamento de Neurociencias, Instituto de Fisiología Celular, Universidad Nacional Autónoma de México, México D.F., \\ 04510, México
}

\begin{abstract}
Consolidation theory proposes that through the synthesis of new proteins recently acquired memories are strengthened over time into a stable long-term memory trace. However, evidence has accumulated suggesting that retrieved memory is susceptible to disruption, seeming to consolidate again (reconsolidate) to be retained in long-term storage. Here we show that intracortical blockade of protein synthesis in the gustatory cortex after retrieval of taste-recognition memory disrupts previously consolidated memory to a restricted degree only if the experience is updated. Our results suggest that retrieved memory can be modified as part of a mechanism for incorporating updated information into previously consolidated memory.
\end{abstract}

The memory consolidation hypothesis has been the major theoretical framework to explain long-term memory storage (McGaugh 1966, 2000). However, it has been reported that memory activated by retrieval becomes susceptible to disruption by the same means that disrupt consolidation (Misanin et al. 1968; Nader et al. 2000). This process, called reconsolidation, suggests that consolidated memory returns to a labile state similar to recently acquired memory each time it is retrieved (Sara 2000; Debiec et al. 2002). However, most of the studies in which reconsolidation process is achieved have used associative learning tasks requiring the association between a conditioned stimulus (CS) and an unconditioned stimulus (US) followed by extinction trials in which the CS is no longer followed by the US. Therefore, during retrieval, when reconsolidation is assessed, there is a competition between the extinction (CS-noUS) and the associative (CS-US) traces, which both require protein synthesis to be retained in long-term memory (Eisenberg et al. 2003; Pedreira and Maldonado 2003). Here we address the post-retrieval consolidation issue on a taste-recognition memory task that allows us to access the formation of memory in the absence of extinction. That is, we used a CS with the same valence during acquisition and retrieval so extinction does not occur and a competition between memories is not established.

Animals exposed to novel taste show reduced consumption (neophobic response). This is followed by graded increases in intake after repeated presentations of the same tastant until a plateau is reached. This behavior is called attenuation of neophobia or AN (Domjan 1977; Buresova and Bures 1980; de VosKorthals and van Hof 1984; Dogterom and van Hof 1988; Bermudez-Rattoni 2004). AN is a long-lasting behavior in which animals must remember a taste as having been experienced previously. This kind of memory is referred as taste-recognition memory (Bermudez-Rattoni 2004), and the insular cortex (IC) (the gustatory neocortex) has been proven to be an important site of gustatory memory formation (Rosenblum et al. 1993;

\footnotetext{
'Corresponding author.

E-mail fbermude@ifc.unam.mx; fax (5255) 56225607.

Article published online ahead of print. Article and publication date are at http://www.learnmem.org/cgi/doi/10.1101/lm.94505.
}

Gutierrez et al. 2003a,b; Bermudez-Rattoni 2004). In AN, the animal exposed to a particular taste will drink more of that solution regardless of the time elapsed between two consecutive taste presentations (Domjan 1976).

Although intracellular pathways for taste memory consolidation (e.g., ERK1/2 and the transcription factor Elk-1; Berman et al. 1998; Berman 2003) have been identified, there is no evidence that cortical protein synthesis is required for long-term AN. Moreover, it has been suggested that after consolidation, retrieval induces a protein-synthesis-dependent process to retain the memory trace in long-term storage (Misanin et al. 1968; Nader et al. 2000; Debiec et al. 2002; Pedreira et al. 2002; Eisenberg et al. 2003). Should this be the case, then a blockade of protein synthesis after retrieval should disrupt the memory trace. Therefore, the aim of the this study was to address this important issue, by using a taste-recognition memory task and injecting anisomycin-a translation inhibitor-infused into the insular cortex under conditions that effectively inhibit $>90 \%$ of protein synthesis in this region (Rosenblum et al. 1993).

\section{Results}

Histological analysis revealed that anisomycin was injected in the IC (Fig. 1). As seen in Figure 2B, animals who received an anisomycin injection into the IC immediately after their first taste presentation ( $0.3 \%$ saccharin) did not exhibit AN on the following day, because their second consumption was similar to their first intake. Injections of artificial cerebrospinal fluid (ACSF) had no effect on AN. The effect of anisomycin was temporal, as increased intake to plateau was observed for succeeding presentations. In addition, when anisomycin was administered $24 \mathrm{~h}$ after the first taste presentation, no effect on AN was observed, indicating that protein synthesis is not required for AN consolidation after $24 \mathrm{~h}$ (Fig. 2B, inset). A repeated measures analysis of variance (ANOVA) revealed a significant effect of group $\left(F_{(2,21)}=14.7, p<0.01\right)$, an effect of trials $\left(F_{(4,84)}=100.23, p<\right.$ $0.01)$, and a group $\times$ trials interaction $\left(F_{(8,84)}=4.80, p<0.01\right)$. Fisher's post-hoc test revealed that the group injected immediately after the first taste presentation was different from the vehicle group and from the group injected $24 \mathrm{~h}$ after 


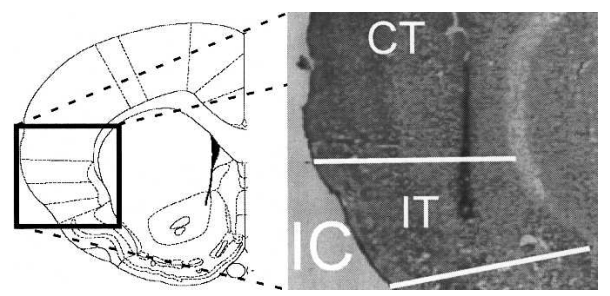

Figure 1. Selected microphotography of a coronal section of an anisomycin-injected rat showing cannula track (CT) and injector tip (IT) location in the insular cortex (IC). Similar results were observed for the rest of the implanted animals. On the left is a coronal diagram of the IC (Reprinted with permission from Elsevier @ 1998, Paxinos and Watson 1998).

$(p<0.01)$. These results indicate that long-term taste-recognition memory requires temporal protein synthesis at specific times in the IC to be consolidated.

As shown by the reduced consumption during the third intake (Fig. 2C), protein synthesis inhibition after the second taste presentation affected previously consolidated memory. This disruption seems to be partial, because a significant increment is observed during the third intake respective to its first one. Furthermore, we found AN disruption by anisomycin after the second intake even when the third taste exposure was delayed for a week (Fig. 2D). An ANOVA with repeated measures revealed a group effect $\left(F_{(3,35)}=4.12, p<0.05\right)$ and a groups $\times$ trials interaction $\left(F_{(12,140)}=5.95, p<0.01\right)$. The post-hoc test revealed that the anisomycin groups were different from their respective vehicle groups ( $\left.p^{\prime} \mathrm{s}<0.01\right)$, as well as from their respective second consumptions ( $\left.p^{\prime} \mathrm{s}<0.01\right)$. Moreover, recent taste experience is necessary to observe memory disruption by anisomycin injections, as anisomycin injected in the absence of a taste presentation did not significantly affect AN (Fig. 2B, inset). These results show that after retrieval the inhibition of protein synthesis causes partial impairment of the previously consolidated taste memory trace, which in turn is dependent on taste experience but not on the time between experiences. Because AN is a graded learning task it follows that, for each taste presentation, a protein-synthesis-dependent process should be initiated to complete the following AN step.

Because AN can be observed as learning steps, it can be assessed to what extent anisomycin treatment disrupted previously consolidated memory after it is retrieved. In this regard, anisomycin applied into the IC immediately after the third taste intake disrupted the last attained AN step while sparing the previous one (Fig. 2E). A repeated measures ANOVA revealed differences only across presentations $\left(F_{(4,80)}=64.49, p<0.01\right)$; however, a paired $t$-test revealed different consumption for the anisomycin group on the fourth taste experience compared with the third consumption $\left(t_{(11)}=4.52, p<0.01\right)$ but was similar to consumption during its second intake. This finding indicates that while updated experience capable of affecting behavior is acquired, part of the older consolidated memory in IC appears not to be dependent on protein synthesis. In addition, when IC protein synthesis was inhibited immediately after the sixth taste intake when AN has clearly reached its plateau, memory was not affected (Fig. 2F). This result suggests that memory is no longer vulnerable to protein synthesis inhibition after asymptotic task performance is reached, presumably because there is no more relevant information to be learned and the older memory has already been consolidated.

An alternative explanation is that the memory returned to a previous step for which the consumption is similar to consumption on the plateau. In this scenario, disruption would not be detected. To discard this possibility, anisomycin infusions into the IC were delivered consecutively. Consistent with the preceding data, we found that after the fourth taste intake, protein synthesis inhibition disrupts to some extent previously consolidated memory, leaving part of the previously consolidated memory unimpaired (Fig. 3A). Repeated measures ANOVA showed a group $\times$ presentations interaction $\left(F_{(7,70)}=2.82\right.$, $p<0.05)$. A further disruption of memory did not occur after two additional anisomycin injections, thereby confirming that part of the previously consolidated memory is independent of protein synthesis in the IC. Finally, three consecutive anisomycin injections into the IC from the 6th to the 8th (Fig. 3B) or from the 11th to the 13th (not shown) taste presentations did not produce aversion and did not disrupt AN behavior.

To further analyze the hypothesis that protein synthesis inhibition impairs previously consolidated memory to a restricted degree only if updating information capable of modifying behavior is integrated to the memory trace, we used an aversive learning task, the conditioned taste aversion (CTA). In this paradigm, a taste (CS) is associated with malaise (US) induced by an intraperitoneal injection of $\mathrm{LiCl}$. We used the associative taste aversion protocol injecting $\mathrm{LiCl}(0.2 \mathrm{M})$ after saccharin intake for three consecutive days. As seen in Figure 3C, a clear taste aversion
A

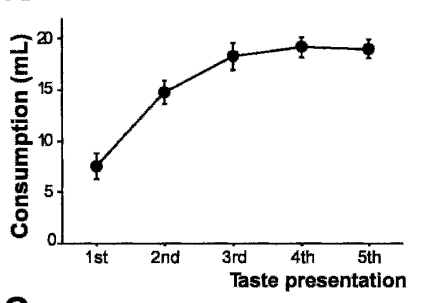

C

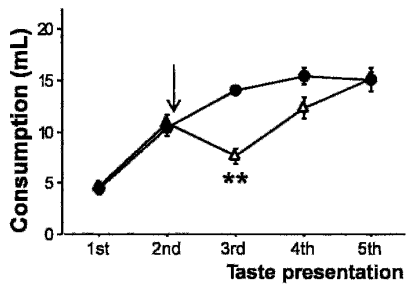

E

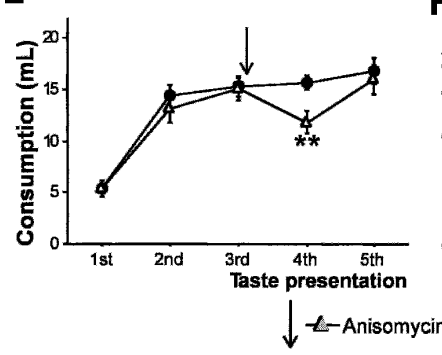

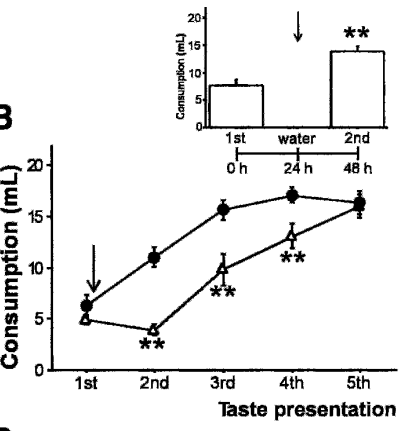

D

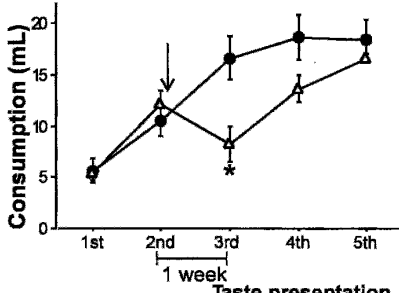

$\mathbf{F}$

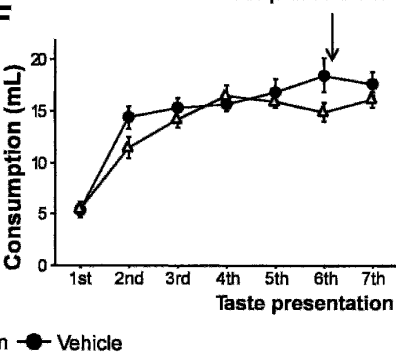

Figure 2. AN typical behavior and protein synthesis inhibition effect on this task. (A) Mean \pm S.E.M. intake (in $\mathrm{mL}$ ) of $0.3 \%$ saccharin on unoperated rats. (B) Anisomycin infusion immediately after the 1 st intake, but not $24 \mathrm{~h}$ later (inset), prevented taste-recognition memory consolidation. $(C, D)$ Anisomycin infusion after the 2 nd taste intake partially disrupted previously consolidated AN, even if the 3rd presentation is delayed for a week. (E) Anisomycin infusion after the 3rd intake disrupted the last attained AN consolidation. ( $F$ ) Anisomycin infusion after the 6th taste intake spared completed AN behavior. (Solid circles) Vehicle; (open triangles) anisomycin. Arrows indicate drug infusion. ${ }^{* *} p<0.01$, ${ }^{*} p<0.05$ between anisomycin-infused and corresponding vehicle groups. 
A

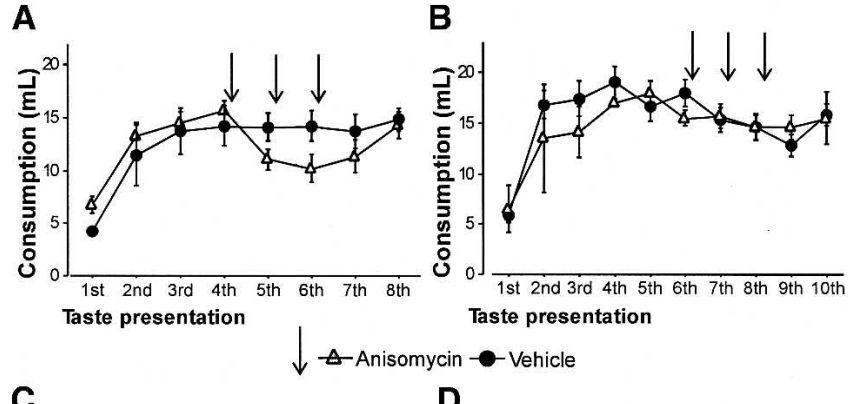

C

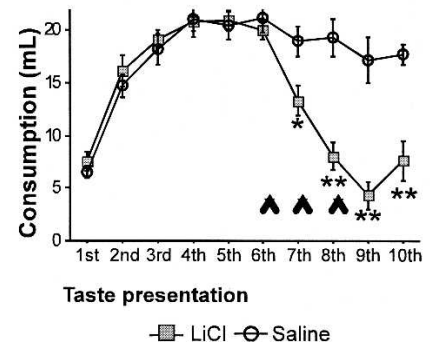

Figure 3. Protein synthesis inhibition in the IC does not impair older consolidated taste memory but disrupts updated aversive experience. (A) Anisomycin injected consecutively after the 4th to the 6th taste presentations disrupted recently consolidated taste memory. (B) Anisomycin injected consecutively after the 6th to the 8th taste presentations spared taste memory. (Solid circles) Vehicle; (open triangles) anisomycin. Arrows indicate drug infusion. (C) A classical malaise agent ( $\mathrm{LiCl}$ ) injected intraperitoneally (i.p.) after the 6th to the 8th saccharin intakes induced an increasing aversion not seen when equivalent volume of saline is injected. $(D)$ Anisomycin injected before taste-malaise association impaired updated aversive experience. (Open circles) Saline; (shaded squares) LiCl. Arrowheads indicate i.p. injections of $\mathrm{LiCl}$ or saline solution. ${ }^{* *} p<0.01$, ${ }^{*} p<0.05$ between treatments.

to $0.3 \%$ saccharin was observed despite the AN having reached its plateau (compare 7th and 9th consumptions for Figure 3, B and $C)$. Repeated measures ANOVA revealed a group $\times$ trials interaction $\left(F_{(9,126)}=13.12, p<0.01\right)$. This shows that taste aversion can be learned for a taste already tagged as a safe stimulus (Bures et al. 1998). The outstanding issue is whether this updating aversive memory requires protein synthesis to be retained in long-term storage. To test this issue, anisomycin was injected into the IC on the 7th taste presentation 15 min before the second CS-US association. As shown in Figure 3D, the anisomycin injection disrupted updating aversive information (CS-US association) as indicated by the significant increase in consumption on the 8th taste presentation. In contrast, the intake in the vehicle-injected group was reduced (Fig. 3D). A repeated measures ANOVA revealed a group $\times$ trials interaction $\left(F_{(7,56)}=2.89, p<0.05\right)$. A $t$ test revealed different consumption for the anisomycin group on the 8th taste experience compared with the vehicle group $\left(t_{(8)}=3.14, p<0.05\right)$. This result demonstrates that protein synthesis is required to update previously consolidated memory trace regardless of the valence of the tastant.

\section{Discussion}

In most associative learning tasks, the presentation of the CS during retrieval initiates memory extinction. Extinction has been considered as a form of learning in which animals learn to associate a CS that is no longer followed by a US (Rescorla 1996; Bouton 2004). For taste aversion and inhibitory avoidance tasks, protein inhibition has been reported to disrupt extinction if CS presentation clearly initiates extinction (Berman and Dudai 2001; Vianna et al. 2001). These studies demonstrate that to re- main in long-term storage, updating extinction memory also requires protein synthesis. However, if CS is presented under conditions in which extinction is not initiated, protein inhibition has been shown to disrupt CS-US association memory (Eisenberg et al. 2003; Pedreira and Maldonado 2003; Sangha et al. 2003). Recently under conditions in which competition between memories does not take place, Duvarci and Nader (2004) and Bozon et al. (2003) found impairment over a previously consolidated memory, by using a retrieval session identical to the training session. Similarly, AN retrieval is achieved by the presentation of the CS of the same valence value, allowing a clearer analysis on consolidation because there is not an extinction process that may establish protein synthesis competition between memories.

This study demonstrates that protein synthesis in the IC is necessary for consolidation and updating consolidation on a taste-recognition memory task. It is important to note that a partial disruption of previously consolidated memory is observed until a response plateau is reached. This impairment is less and less noticeable as maximum performance is attained. Increasing the dosage is unlikely to produce further disruption because the dose of anisomycin we employed inhibits more than $90 \%$ of protein synthesis on the IC (Rosenblum et al. 1993). In addition, there is evidence that changes in the retrieval conditions may result in a re-susceptibility of well-consolidated memories to protein synthesis inhibition. In this regard, Suzuki et al. (2004) reported that weak memories are more easily reconsolidated than strong memories. Strong memories require longer reminders to undergo reconsolidation. So, whether different retrieval conditions than those used here (e.g., a longer test session) might reveal an impairment of a well-consolidated taste memory remains to be ascertained. Nevertheless, our results suggest that protein synthesis is required for integrating updating information to an already consolidated memory. Therefore, our main conclusion is that part of the previously consolidated memory requires protein synthesis only if updated experience capable of modifying behavior is acquired.

Several reports have suggested that memory consolidation requires several molecular mechanisms shared by post-retrieval consolidation (Przybyslawski and Sara 1997; Przybyslawski et al. 1999; Kida et al. 2002; Pedreira et al. 2002; Bozon et al. 2003), raising the possibility that post-retrieval consolidation is a recapitulation of the original cellular mechanisms for memory consolidation (Sara 2000). However, this interpretation is not supported by other studies (Hall et al. 2001; Tronel and Sara 2002; Kelly et al. 2003). In this regard, in the hippocampus the transcription factor C/EBP $\beta$ was shown to be required for consolidation but not for post-retrieval consolidation for an inhibitory avoidance task (Taubenfeld et al. 2001). More recently, cellular dissociation between consolidation and post-retrieval consolidation has been described for hippocampus-dependent contextual fear conditioning, consolidation being dependent on BrainDerived Neurotropic Factor (BDNF) and post-retrieval consolidation on the transcription factor zif268 (Lee et al. 2004). Furthermore, it has recently been reported that muscarinic receptors activity in the IC is required for AN consolidation but not for AN post-retrieval consolidation (Gutierrez et al. 2003b). These results and our results suggest dissociation between these two processes. That is, post-retrieval consolidation seems to be sensitive to anisomycin infusions but not to a muscarinic antagonist, and consolidation seems to be sensitive to both muscarinic antagonist and anisomycin infusions under similar circumstances (same region and task). The results of our study suggest that cellular events underlying memory are not recapitulated every time memory is retrieved. Instead, it appears that when experience capable of affecting behavior is acquired, a protein-synthesis- 
dependent process is initiated to integrate the updated experience with the previously consolidated memory. Accordingly, when no more relevant information is obtained and the performance remains stable, the protein synthesis is no longer required.

In summary, our data suggest that a taste memory trace is not the same each time it is retrieved. Instead, retrieved memory seems to be a state in which updated information is incorporated into an already acquired background either to strengthen (next AN step) or change (e.g., aversive information) a memory trace. We provided evidence that post-retrieval consolidation is not a rewriting for memory as a whole but a state in which the acquisition of updated information into a dynamic memory framework is still possible.

\section{Materials and Methods}

\section{Subjects}

Male Wistar rats from Instituto de Fisiología Celular breeding colony weighing between 280 and $320 \mathrm{~g}$ at the beginning of the experiment were housed individually in plastic cages and kept on a $12 \mathrm{~h}$ light/12 h dark cycle. All manipulations were performed during the light cycle. Food was freely available throughout experiments. Experiments were performed in accordance with the Rules in Health Matters (Ministry of Health, Mexico) and with approval of the local Animal Care Committee.

\section{Surgery and microinjection}

Animals under sodium pentobarbital $(65 \mathrm{mg} / \mathrm{kg})$ anesthesia were bilaterally implanted with stainless-steel guide cannulae in the insular cortex. Coordinates from Bregma were anterior $1.2 \mathrm{~mm}$, lateral $\pm 5.5 \mathrm{~mm}$, and ventral $-4 \mathrm{~mm}$ (Paxinos and Watson 1998). Five days after surgery, the behavioral procedures were performed. For bilateral microinjections, an injector was inserted into each guide cannula extending $2 \mathrm{~mm}$ below cannula tip. Drugs ( $1 \mu \mathrm{L}$ per hemisphere) were infused over a minute and the injector was left in place for an additional minute to allow diffusion. Anisomycin (Sigma) was dissolved in equimolar $\mathrm{HCl}$ and adjusted to $100 \mathrm{mg} / \mathrm{mL}$, pH 7.5 in vehicle solution (ACSF: 125 $\mathrm{mM} \mathrm{NaCl}, 5 \mathrm{mM} \mathrm{KCl}, 1.25 \mathrm{mM} \mathrm{NaH}_{2} \mathrm{PO}_{4} \cdot \mathrm{H}_{2} \mathrm{O}, 1.5 \mathrm{mM}$ $\mathrm{MgSO}_{4} \cdot 7 \mathrm{H}_{2} \mathrm{O}, 26 \mathrm{mM} \mathrm{NaHCO}_{3}, 10 \mathrm{mM}$ glucose, $2.5 \mathrm{mM} \mathrm{CaCl}_{2}$ ). Rats were handled on several days before injection to prevent stress.

\section{Behavioral procedures}

Rats were deprived of water for $24 \mathrm{~h}$. Then, they were allowed to drink water once a day. After three consecutive days of water intake, on day 4 , rats received saccharin $(0.3 \% \mathrm{w} / \mathrm{v})$ solution for the first time as the neophobia trial. Unless otherwise indicated, on following days the saccharin solution was presented daily to assess AN behavior. To avoid dehydration, water access was given after each saccharin intake. All consumption periods were 15 min long and the volumes ingested were recorded.

For the experiment presented in Figure 3C, the 0.3\% saccharin solution on the 6 th to the 8th taste intakes was followed by intraperitoneal injection of either $\mathrm{LiCl}(0.2 \mathrm{M}, 10 \mathrm{~mL} / \mathrm{Kg})$ or an equivalent amount of saline, $30 \mathrm{~min}$ after intake onset.

For the experiment presented in Figure 3D, the $0.3 \%$ saccharin solution was followed by intraperitoneal injection of $\mathrm{LiCl}$ $(0.2 \mathrm{M}, 10 \mathrm{~mL} / \mathrm{Kg})$ on the 6 th and the 7 th taste intakes. Anisomycin or vehicle solution was infused 15 min before the 7 th taste presentation.

\section{Histology}

At the end of the experiments, rats were perfused and their brains removed. Brain sections ( $40 \mu \mathrm{m}$ thick) were stained with cresyl violet and examined by light microscopy for injector tip placement.

\section{Statistical analysis}

Repeated measures analysis of variance (ANOVA) was used to compare mean \pm S.E.M. intake of saccharin among groups across trials. The Fisher pairwise test was used for post-hoc analysis, with $p<0.05$ considered significant. A $t$-test was used to compare intake between groups on a particular trial.

\section{Acknowledgments}

We thank Dr. Sid Simon and Jennifer Stapleton for helpful comments. We also thank Federico Jandete, Oreste Carbajal, Francisco Pérez Eugenio, and Yolanda Díaz de Castro for technical assistance. This study was supported by CONACYT-México 42657 and DGAPA.-UNAM IN-202504.

\section{References}

Berman, D.E. 2003. Modulation of taste-induced Elk-1 activation by identified neurotransmitter systems in the insular cortex of the behaving rat. Neurobiol. Learn. Mem. 79: 122-126.

Berman, D.E. and Dudai, Y. 2001. Memory extinction, learning anew, and learning the new: Dissociations in the molecular machinery of learning in cortex. Science 291: 2417-2419.

Berman, D.E., Hazvi, S., Rosenblum, K., Seger, R., and Dudai, Y. 1998. Specific and differential activation of mitogen-activated protein kinase cascades by unfamiliar taste in the insular cortex of the behaving rat. J. Neurosci. 18: 10037-10044.

Bermudez-Rattoni, F. 2004. Molecular mechanisms of taste-recognition memory. Nat. Rev. Neurosci. 5: 209-217.

Bouton, M.E., 2004. Context and behavioral processes in extinction. Learn. \& Mem. 11: 485-494.

Bozon, B., Davis, S., and Laroche, S. 2003. A requirement for the immediate early gene zif268 in reconsolidation of recognition memory after retrieval. Neuron 40: 695-701.

Bures, J., Bermudez-Rattoni, F., and Yamamoto, T. 1998. Conditioned taste aversion: Memory of a special kind. Oxford Science Publications, New York.

Buresova, O. and Bures, J. 1980. Post-ingestion interference with brain function prevents attenuation of neophobia in rats. Behav. Brain Res. 1: 299-312.

Debiec, J., LeDoux, J.E., and Nader, K. 2002. Cellular and systems reconsolidation in the hippocampus. Neuron 36: 527-538.

de Vos-Korthals, W.H. and van Hof, M.W. 1984. The effect of hypobaric hypoxia on taste neophobia in rats. Behav. Brain Res. 14: 157-159.

Dogterom, G.J. and van Hof, M.W. 1988. Attenuation of neophobia and conditioned taste aversion in the rabbit. Behav. Brain Res. 28: $253-257$.

Domjan, M. 1976. Determinants of the enhancement of flavored-water intake by prior exposure. J. Exp. Psychol. Anim. Behav. Process 2: $17-27$.

. 1977. Attenuation and enhancement of neophobia for edible substances. In Learning mechanisms in food selection (ed. L.M. Barker, M.R. Best, and M. Domjan), pp. 151-180. Baylor University Press, Waco, TX.

Duvarci, S. and Nader, K. 2004. Characterization of fear memory reconsolidation. J. Neurosci. 24: 9269-9275.

Eisenberg, M., Kobilo, T., Berman, D.E., and Dudai, Y. 2003. Stability of retrieved memory: Inverse correlation with trace dominance. Science 301: 1102-1104.

Gutierrez, R., Rodriguez-Ortiz, C.J., De La Cruz, V., Nunez-Jaramillo, L., and Bermudez-Rattoni, F. 2003a. Cholinergic dependence of taste memory formation: Evidence of two distinct processes. Neurobiol. Learn. Mem. 80: 323-331.

Gutierrez, R., Tellez, L.A., and Bermudez-Rattoni, F. 2003b. Blockade of cortical muscarinic but not NMDA receptors prevents a novel taste from becoming familiar. Eur. J. Neurosci. 17: 1556-1562.

Hall, J., Thomas, K.L., and Everitt, B.J. 2001. Fear memory retrieval induces CREB phosphorylation and Fos expression within the amygdala. Eur. J. Neurosci. 13: 1453-1458.

Kelly, A., Laroche, S., and Davis, S. 2003. Activation of mitogen-activated protein kinase/extracellular signal-regulated kinase in hippocampal circuitry is required for consolidation and reconsolidation of recognition memory. J. Neurosci. 23: 5354-5360.

Kida, S., Josselyn, S.A., Peña Ortiz, S., Kogan, J.H., Chevere, I., Masushige, S., and Silva, A.J. 2002. CREB required for the stability of new and reactivated fear memories. Nat. Neurosci. 5: 348-355.

Lee, J.L.C., Everitt, B.J., and Thomas, K.L. 2004. Independent cellular processes for hippocampal memory consolidation and reconsolidation. Science 304: 839-843.

McGaugh, J.L. 1966. Time-dependent processes in memory storage. Science 153: 1351-1358.

\section{Learning \& Memory}


2000. Memory-A century of consolidation. Science 287: $248-251$

Misanin, J.R., Miller, R.R., and Lewis, D.J. 1968. Retrograde amnesia produced by electroconvulsive shock after reactivation of a consolidated memory trace. Science 160: 554-555.

Nader, K., Schafe, G.E., and LeDoux, J.E. 2000. Fear memories require protein synthesis in the amygdala for reconsolidation after retrieval. Nature 406: 722-726.

Paxinos, G. and Watson, C. 1998. The rat brain in stereotaxic coordinates. Academic Press, San Diego, CA.

Pedreira, M.E. and Maldonado, H. 2003. Protein synthesis subserves reconsolidation or extinction depending on reminder duration. Neuron 38: 863-869.

Pedreira, M.E., Perez, C., and Maldonado, H. 2002. Reactivation and reconsolidation of long-term memory in the crab Chasmagnathus: Protein synthesis requirement and mediation by NMDA-type glutamatergic receptors. J. Neurosci. 22: 8305-8311.

Przybyslawski, J. and Sara, S.J. 1997. Reconsolidation of memory after its reactivation. Behav. Brain Res. 84: 241-246.

Przybyslawski, J., Roullet, P., and Sara, S.J. 1999. Attenuation of emotional and nonemotional memories after their reactivation: Role of $\beta$ adrenergic receptors. J. Neurosci. 19: 6623-6628.

Rescorla, R.A. 1996. Preservation of pavlovian associations through extinction. Q. J. Exp. Psychol. B 49: 245-258.

Rosenblum, K., Meiri, N., and Dudai, Y. 1993. Taste memory: The role of protein synthesis in gustatory cortex. Behav. Neural Biol. 59: $49-56$.

Sangha, S., Scheibenstock, A., Morrow, R., and Lukowiak, K. 2003. Extinction requires new RNA and protein synthesis and the soma of the cell right pedal dorsal 1 in Lymnaea stagnalis. J. Neurosci. 23: 9842-9851.

Sara, S.J. 2000. Retrieval and reconsolidation: Toward a neurobiology of remembering. Learn. \& Mem. 7: 73-84.

Suzuki, A., Josselyn, S.A., Frankland, P.W., Masushige, S., Silva, A.J., and Kida, S. 2004. Memory reconsolidation and extinction have distinct temporal and biochemical signatures. J. Neurosci. 24: 4787-4795.

Taubenfeld, S.M., Milekic, M.H., Monti, B., and Alberini, C.M. 2001. The consolidation of new but not reactivated memory requires hippocampal C/EBPß. Nat. Neurosci. 4: 813-818.

Tronel, S. and Sara, S.J. 2002. Mapping of olfactory memory circuits: Region-specific c-fos activation after odor-reward associative learning or after its retrieval. Learn. \& Mem. 9: 105-111.

Vianna, M.R.M., Szapiro, G., McGaugh, J.L., Medina, J.H. and Izquierdo, I. 2001. Retrieval of memory for fear-motivated training initiates extinction requiring protein synthesis in the rat hippocampus. Proc. Natl. Acad. Sci. 98: 12251-12254.

Received March 11, 2005; accepted in revised form June 16, 2005. 


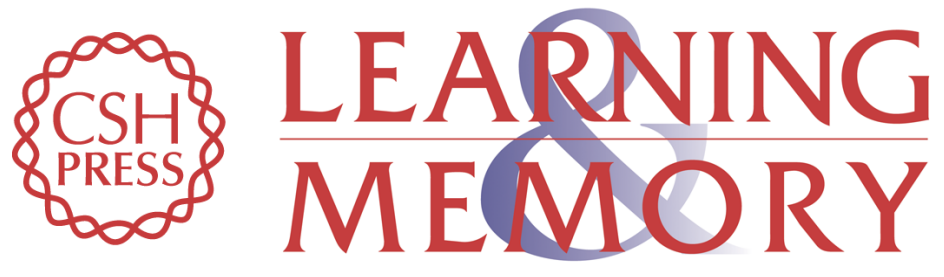

\section{Protein synthesis underlies post-retrieval memory consolidation to a restricted degree only when updated information is obtained}

Carlos J. Rodriguez-Ortiz, Vanesa De la Cruz, Ranier Gutiérrez, et al.

Learn. Mem. 2005, 12:

Access the most recent version at doi:10.1101/lm.94505

References This article cites 35 articles, 17 of which can be accessed free at: http://learnmem.cshlp.org/content/12/5/533.full.html\#ref-list-1

License

Email Alerting Receive free email alerts when new articles cite this article - sign up in the box at the Service top right corner of the article or click here. 